\title{
PLANEJAMENTO PROGRAMAÇÃO E CONTROLE DE PRODUÇÃO: Sistema Just In Time
}

João Pedro Sousa BESERRA ${ }^{1}$

Antonio Carlos ESTENDER ${ }^{2}$

\begin{abstract}
${ }^{1}$ Bacharel em Administração. Universidade de Guarulhos. joaopedrosousa52@gmail.com
${ }^{2}$ Mestre em Administração e professor da Universidade de Guarulhos. estender@uol.com.br
\end{abstract}

Recebido em: 15/05/2016 - Aprovado em: 16/10/2016 - Disponibilizado em: 18/12/2016

\begin{abstract}
RESUMO:
O presente trabalho busca gerar conhecimentos para a aplicação prática, visa também solucionar problemas específicos, no caso de que porque o planejamento programação e controle de produção é tão importante para o cumprimento dos prazos de entregas estabelecidos pela demanda de uma indústria química, verificar os benefícios do planejamento programação e controle de produção visando o cumprimento das datas de entregas dos produtos, com ênfase na produtividade graduada e compreender o ambiente fabril, para a fábrica trabalhar em total sintonia com o planejamento programação e controle de produção; no ramo químico. O trabalho foi realizado por meio de estudo de caso, entrevistas, de natureza qualitativa e exploratória, sendo a coleta de dados realizada através de um questionário destinado aos colaboradores. Foram encontradas algumas falhas no processo do departamento de planejamento programação e controle de produção, que tinham total influencia no processo produtivo do produto. Após o estudo realizado com base nos dados coletados, foi definido que para eliminar essas falhas deve-se ser implantado o sistema Just in time.
\end{abstract}

Palavras chave: Planejamento. Demanda. Estoque. Processo. Produção.

\section{PLANNING PROGRAMMING AND PRODUCTION CONTROL: System Just In Time}

\begin{abstract}
:
This study seeks to generate knowledge for practical application, also aims to solve a specific problem in the case that because planning programming and production control is so important to meet the delivery deadlines set by the demand of the chemical industry. verify the benefits of planning programming and production control order to comply with delivery dates of products, with an emphasis on productivity and graduated understand the manufacturing environment, to the factory to work in tune with the planning programming and production control; in the chemical industry. Was conducted through case studies, interviews, qualitative and exploratory nature, with data collection conducted through a questionnaire for employees. Through the collection of data found some flaws in the planning department process programming and production control, which had overall influence in the production of the product process. After the study based on the data collected, it was decided that to eliminate these failures should be deployed the system Just in Time.
\end{abstract}

Keywords: Planning. Demand. Stock. Process. Production.

\section{Introdução}

Slack (2002), Bastos (2006) vêm analisando o tema, conforme apontado na revisão de literatura, em seus diferentes níveis de entendimento e aplicação ao contexto organizacional. Pode-se encontrar na literatura definições para planejamento programação e controle de produção na 
indústria química e analisar o planejamento programação e controle de produção, para o cumprimento de datas estabelecidas pela demanda, com base no sistema Just in time o que demanda a construção de um modelo teórico/gerencial que explicite como esses diferentes conceitos se articulam e podem contribuir para o entendimento de propostas do desenvolvimento organizacional.

\section{$\mathrm{O}$ planejamento programação e} controle de produção apoiou a produção em massa para obter o melhor planejamento de recursos para que ocorra uma produção mais eficaz sua expansão ocorreu devido aos sistemas computacionais que com maior complexidade e com uma abrangência, maior acaba envolvendo diversos setores da organização e fornecedores de matéria-prima como novidade citar as práticas da manufatura enxuta originárias na empresa Toyota um modo revolucionário de produzir com estoques mínimos de matéria-prima, eliminando desperdícios presentes na produção, criando o modelo de excelência operacional, a evolução do planejamento programação e controle de produção dependem de novas tecnologias e da capacidade do envolvido e da socialização das práticas de planejamento programação e controle de produção (PPCP), questiona como as empresas vêm projetando seu PPCP em busca de melhor eficiência operacional.

$\mathrm{Na}$ literatura acadêmica sobre planejamento programação e controle de produção na indústria química e analisar o planejamento programação e controle de produção, para o cumprimento de datas estabelecidas pela demanda, com base no sistema Just in Time, relacionados com o setor químico existem poucos estudos sobre o tema (BURGESS et al, 2005). Os trabalhos identificados na literatura do Brasil.

Como o planejamento programação e controle de produção age nas organizações?; Porque o planejamento programação e controle de produção é tão importante para o cumprimento dos prazos de entregas estabelecidos pela demanda de uma indústria química?; Quais os benefícios que o planejamento programação e controle de produção traz para o gerenciamento de estoque da organização com base no sistemas Just in time?.

Refletir a importância do planejamento programação e controle de produção é importante para o cumprimento dos prazos de entregas estabelecidos pela demanda na indústria química; verificar os benefícios do Planejamento programação e controle de produção visando o cumprimento das datas de entregas dos produtos, com ênfase na produtividade graduada e compreender o ambiente fabril, para a fábrica trabalhar em total sintonia com o PPCP; compreender a implantação das datas estabelecidas pela demanda, descobrir as melhores alternativas para derrubar barreiras que surgem no processo produtivo, visando 
aumentar a lucratividade da empresa; identificar quais são as opiniões dos funcionários/colaboradores; elaborar ações baseadas nas percepções das situações vivenciadas pelos funcionários/colaboradores para produção de ações que possibilitem atingir estes objetivos, com base no sistema Just in time.

O PPCP tem como função conciliar o planejamento estratégico com as atividades desempenhadas diariamente no "chão de fábrica". Por isso, é necessário reunir informações vindas de diversas áreas do sistema produtivo, como foi citado anteriormente. O PPCP é o elo entre o estratégico, tático e operacional. Assim, é necessário que o responsável pelo PPCP da empresa seja uma pessoa extremamente dinâmica e flexível, com capacidade de tomar decisões rápidas e acertadas, com objetivo de aumentar lucratividade da empresa.

O presente estudo visa a contribuir para a elucidação de questões relacionadas aos dois temas: planejamento programação e controle de produção na indústria química e analisar o planejamento programação e controle de produção, para o cumprimento de datas estabelecidas pela demanda, com base no sistema Just in Time nas empresas; O planejamento programação e controle de produção têm como foco desenvolver $\mathrm{o}$ processo industrial de forma que auxilia a tomada de decisões táticas e operacionais fazendo uma interligação entre os departamentos de vendas, compras, almoxarifado, produção, com intuito de propor alternativas para esses departamentos para que sejam concluído os prazos estabelecidos pela demanda e gerar lucros.

Este setor é um dos mais, senão o mais importante, para muitas empresas, principalmente no caso de uma indústria química, pois pode impactar diretamente no sucesso da empresa. Um bom planejamento de produção, além de eliminar desperdícios, aumenta a competitividade da organização. Por outro lado, um mau planejamento da demanda pode ocasionar no fracasso de uma empresa; Almeja-se preencher a lacuna empírica/gerencial identificada na relação entre planejamento programação e controle de produção na indústria química e analisar o planejamento programação e controle de produção, para o cumprimento de datas estabelecidas pela demanda, com base no sistemas Just in time. O presente estudo constitui uma contribuição para compreender os fatores competitivos do ramo químico.

Para o desenvolvimento da pesquisa, em termos metodológicos, será adotada a abordagem qualitativa. Segundo Collis; Hussey (2005) as pesquisas deste tipo se caracterizam pela interrogação direta das pessoas cujo comportamento se deseja conhecerem. Basicamente, procede-se à solicitação de informações via questionários a um grupo significativo de pessoas acerca do problema estudado para em seguida, mediante 
análise, obter as conclusões correspondentes aos dados coletados. A população $\begin{array}{llll}\text { entrevistada foi } & \text { de }\end{array}$ funcionários/colaboradores de diferentes hierarquias, as amostras foram analisadas de forma empírica na empresa Brazilian Color na cidade de Guarulhos.O estudo está estruturado em cinco seções, além desta introdução.

\section{Planejamento programação e controle de} produção, com base no sistemas Just in time

Segundo Slack (2002) o propósito do planejamento e controle é garantir que os processos da produção ocorram eficaz e eficientemente e que produzam produtos e serviços conforme requeridos pelos consumidores; porém para uma empresa ser competitiva através de seu planejamento programação e controle de produção é necessário que os departamentos financeiros, vendas, compras de marketing e de produção estejam integrados possibilitando desta forma a implementação dos programas de PPCP no ambiente fabril.

O sistema de produção que elimina desperdícios, ou seja, só vai ser produzido aquilo que é necessário nada é comprado antes do tempo. A melhor forma de implantar esse sistema na nossa organização seria eliminar o estoque de produto acabado, matéria-prima e produzir somente quando tiver um pedido colocado por vendas, mediante esse pedido seria emitido uma ordem de compra de matéria-prima, acredito que seria importante oferecer um treinamento a todos os colaboradores envolvidos no processo produtivo para reduzir ao máximo o número de erros.

Segundo Plossl (1993) A administração deve tomar a liderança no desenvolvimento dos programas educacionais necessários para superar as limitações do passado e preparar todo o seu o pessoal para o futuro; portanto a organização deve tomar ciência que treinamento é fundamental para que os colaboradores estejam preparados para mudanças em equipamentos industriais.

Segundo Boog (2009) eliminar desperdícios significa analisar todas as atividades realizadas na fábrica e descontinuar as que não agregam valor à produção; como também para eliminar alguma atividade do processo produtivo, deve se haver um estudo do processo, para não eliminar alguma que interfere diretamente ao valor do produto acabado.

De acordo Moreira (2008) gerenciar os estoques de todos esses itens com a mesma atenção e os mesmos métodos pode ser bastante dispendioso, obrigando a que se encontre alguma forma de dar atenção diferenciada a certos itens; quando uma empresa que se tornar competitiva ela deve elevar ao máximo seu lucro sobre o capital, por isso é de suma importância que seja 
realizado um controle de seus estoques bem detalhado, para que sai na frente de seus concorrentes.

De acordo Bastos (2006) o Just in time (JIT) foi desenvolvido diante da necessidade de reduzir custos de produção por meio da eliminação do excesso e do desperdício em todas as etapas do processo produtivo; portanto o JIT tem a função de alocar a matéria prima, na quantidade e no tempo necessário. Ele está relacionado com a produção por demanda, ou seja, a venda do produto ativa e puxa todo processo produtivo.

De acordo Rebouças (2011) a administração de processos pode, e deve cancelar produtos ou serviços que não alavanquem ou apresentem resultados satisfatórios; mas também deve se gerar um plano de produção de produtos finais que sejam aproximadamente corretos para que não se perca tempo com o reprocessamento de processos e acrescente custos adicionais que não estão no seu processo.

De acordo Silva (1973) a melhor forma de controlar a eficiência dos operários, seria motivando-os para obtenção de melhor produtividade; portanto o sistema de controle de eficiência é a forma de ter total controle sobre a eficiência dos colaboradores, buscando sempre motivando-os para que melhorem seu rendimento.

Produzir aquilo que é vendido nada é comprado ante da hora para eliminar ao máximo os desperdícios, melhor forma de implantar acredito que de inicio seria bom haver uma preparação de terreno, ou seja oferecer treinamentos aos colaboradores, pois eles são as células da empresa, é preciso acertar prazos com fornecedores e eliminar todos os estoques da fábrica.

Segundo Harding (1989) para que fossem mantidos estoques adequados de materiais, capazes de manter a produção trabalhando sem interrupções, deveria haver uma sequência lógica ou uma regra para encomendas; portanto têm que haver um planejamento de vendas, para que não sejam colocados pedidos que atropelem o processo produtivo, devido as negociações realizadas com os clientes.

De acordo Ofenhejm (2008) uma articulação de recursos organizacionais, um aprendizado da organização, um saber-fazer coletivo e complexo, especialmente no que se diz respeito à coordenação de diversas habilidades de produção; portanto Competência Organizacional é um aprendizado coletivo dos colaboradores envolvidos no processo produtivo em conjunto.

De acordo Oliveira (2006) visa as atividades e as ordens para executá-las, que devem ser cumpridas de forma correta na data e hora esperada; mas para que atividades sejam realizadas com extrema eficiência é preciso que alguém monitore e também relate todo acontecido durante o processo. 
De acordo Duarte (2011) conjunto dos recursos organizacionais, tais como humanos, financeiro, materiais e tecnológicos, capazes de influir no microambiente, isto é, no interior da organização; portanto o ambiente interno da empresa é formado pelo conjunto de recursos físicos, humanos e financeiros, entre outros, sobre os quais é possível exercer controle, pois resultam das estratégias definidas pelos gestores.

Nada pode ser produzido sem ser na hora exata, esse sistema serve para reduzir os custos da empresa, bom primeiro acredito que deveria ter uma reestruturação na equipe, depois a organização deveria fazer treinamentos com alguns colaboradores para iniciar a implantação, para produzirem com qualidade.

Segundo Ritzman (2004) gerenciar o estoque de demanda independente pode ser complicado, porque a demanda é influenciada por fatores externos; porém se houver um estudo antes de fechar uma negociação, pode se preparar com antecedência a situações que possam ocorrer.

De acordo Corrêa (2001) é muito importante que a empresa saiba utilizar todas as ferramentas disponíveis para conseguir antecipar a demanda futura com a alguma precisão; portanto saber das informações trazidas pelos clientes é de suma importância tanto para o gerente de PPCP quanto para os colaboradores do setor de vendas. Promessas de prazos garantem o desempenho em confiabilidade de entrega e em caso de não atendimento da demanda, decidir quais clientes serão priorizados e os que terão de esperar.

De acordo Rocha produtividade é definida como a relação (razão) entre a quantidade produzida (Q) e o recurso que lhe deu origem; como também produtividade é a redução do tempo gasto para executar um serviço, ou o aumento da qualidade de produtos elaborados, com a manutenção dos níveis de qualidade, sem o acréscimo de mão-de-obra ou aumento dos recursos necessários.

Após serem citados acima foi encontrado algumas semelhanças e diferenças entre alguns autores, as semelhanças que foram encontradas foi que grande parte dos autores fazem citações sobre o processo produtivo e de que forma deve ser executa-lo. A Principal diferença encontrada foi que apenas somente um autor Plossl (1993) sugere treinamentos para que o processo produtivo seja realizado com eficiência.

\section{Aspectos Metodológicos}

\section{Métodos}

O Estudo de Caso como método que apresenta melhor aderência ao objetivo e às questões norteadoras do trabalho. Tull e Hawkins (1976, p. 323) afirmam que "um estudo de caso se refere a uma análise intensiva de uma situação particular". De acordo com (YIN, 2005), a preferência pelo 
uso do estudo de caso deve ser no estudo de eventos contemporâneos, em situações onde os comportamentos relevantes não podem ser manipulados, mas onde é possível se fazer observações diretas e entrevistas.

Para Quivy; Campenhoudt (1998), no método de observação é importante ressaltar que este implica um alto grau de subjetividade, uma vez que as pessoas se manifestam de acordo com sua vivência, histórico de valores e aspectos culturais. Utiliza-se este tipo de pesquisa empírica quando se quer conseguir informações e conhecimento referentes a um determinado problema do qual se busca comprová-lo, ou ainda, com a intenção de descobrir novos fenômenos, percepções ou relações entre eles. O termo pesquisa empírica, concisamente, se define como: (1) o modo de fazer pesquisa por meio de um objeto localizado dentro de um recorte do espaço social. A pesquisa empírica está centrada na escolha de aspectos das relações entre sujeitos. (2) A pesquisa empírica lida com processos de interação e face-a-face, isto é, o pesquisador não pode elaborar a pesquisa em "laboratório" ou em uma biblioteca, isolada e apenas com livros a sua volta. Nesta modalidade da elaboração do conhecimento, o pesquisador precisa "ir ao campo".

O conhecimento empírico é conceituado por Fachin (2003) como a resposta para ocorrências baseadas na vivência, experiência de erros e acertos, que não possuem fundamentação metodológica. Já para Ramos; Ramos; Busnello (2005) acrescenta o conceito anterior a concepção do autor em que o conhecimento empírico é estabelecido pela experiência do outro da interação humana e social, na qual são explicitados conhecimentos implícitos individuais. Dentre as metodologias ao nosso alcance, os pesquisadores as agrupam em dois níveis: 1. Metodologias Qualitativas e Observação-participante. 2. Entrevistas nãoestruturadas e/ou depoimentos. A pesquisa empírica implica em refletir acerca da relação que se estabelece entre o sujeito e o objeto da pesquisa.

\section{Análise da Unidade}

Fundada por Clair José de Carvalho, Edson José de Carvalho, Osmar José de Carvalho na data de 21 de março de 1988 no Bairro: Granja Eliana em Guarulhos São Paulo, especializada na fabricação de tintas para plásticos, repintura automotiva, automotiva original e metais, vem iniciando recentemente a produção de tintas imobiliária.

A princípio sua planta possuía $100 \mathrm{~m}^{2}$, após investimentos sua planta atualmente possui $14000 \mathrm{~m}^{2}$ e se localiza no mesmo endereço da sua fundação com 112 colaboradores, iniciou suas atividades com produções de pastas de tingimento, e tinta para pintura de gravação de fios elétricos, seu produto carro-chefe atualmente é tintas da repintura automotiva. 
O problema no departamento de planejamento programação e controle de produção, pois muitas vezes os colaboradores da área não se atentam ao levantamento do estoque de matéria-prima com atenção e emitem ordens de compras de matéria-prima totalmente divergentes com o que realmente necessita, não têm uma programação ordens de compras são enviadas para chegar com um intervalo de um dia para outro, isso afeta de maneira diretamente o departamento de compras que necessita de um prazo para realizar cotações o que acaba atrasando a chegada de algumas matérias-primas, afetando os prazos de entregas dos produtos; muitas vezes acaba chegando matéria-prima que seu espaço já está completo, e acaba tendo que haver uma nova organização no estoque. Devido algumas ordens de fabricação serem emitidas em caráter de urgência, muitas vezes o processo produtivo não é realizado de forma correta o que acaba interferindo o resultado final do produto.

\section{Coleta e Análise de Dados}

A análise das entrevistas foi feita de maneira empírica e interpretativa, por meio da utilização da análise de conteúdo. Segundo (GUBRIUM; HOLSTEIN, 2000) esse tipo de pesquisa busca apontar os "comos", e os "por quês" embasados nos discursos oriundos da análise das entrevistas levando-se em consideração as significações, procurando identificar as percepções dos funcionários/colaboradores sobre o tema. Um dos propósitos da utilização das entrevistas como método de coleta de dados na pesquisa qualitativa, explorar percepções, experiências, crenças e/ou motivações dos funcionários/colaboradores sobre questões específicas no campo organizacional.

A análise foi feita em duas etapas: a) análise e compreensão das pesquisas bibliográficas e/ou documentais feitas sobre o tema; b) análise e compreensão das entrevistas realizadas. Sabe-se que, desse modo, a metodologia qualitativa na pesquisa empírica, ao estabelecer relações face-a-face entre o "sujeito que pesquisa" com o "sujeito que é pesquisado", permite vínculos de reflexão entre as partes envolvidas porque estão todos em presença, isto é, frente-afrente e em diálogo. A entrevista qualitativa pode ser utilizada para provocar a expressão e opinião do entrevistado sobre as questões emanadas do objetivo geral e dos objetivos específicos da pesquisa, buscar as conexões conceituais entre o mundo do respondente e o Referencial Teórico, além de entender a lógica, passo a passo, de uma situação que não está clara (Easterby- Smith, 1999).

Em conformidade com Flores (1994), o roteiro de entrevistas foi elaborado em função dos objetivos e da questão de pesquisa, e foi guiado pelos principais tópicos levantados. Sendo uma pesquisa qualitativa, não existe uma rígida delimitação em relação ao número adequado de sujeitos da entrevista, 
pois é um dado que pode sofrer alterações no decorrer do estudo, além disso, pode haver necessidade de complementação de informações, ou também, em caso de esgotamento, à medida que as respostas se tornam redundantes.

As entrevistas para esse trabalho foram realizadas individualmente no local de trabalho. Estas foram realizadas entre os dias 08/03 e 29/04 do ano de 2016. Para se atingir os propósitos desse estudo buscou-se formular um roteiro de entrevista embasado na teoria descrita. Os dados foram levantados por meio de pesquisa bibliográfica, pesquisa de campo e entrevistas em profundidade, com questões não estruturadas com 23 colaboradores da empresa Brazilian Color, atuantes na cidade de Guarulhos, ligados à área de química.

O objetivo é verificar os benefícios do planejamento programação e controle de produção, visar o cumprimento das datas de entregas dos produtos, com ênfase na produtividade graduada e compreender $\mathbf{o}$ ambiente fabril, para a fábrica trabalhar em total sintonia com o PPCP, compreender a implantação das datas estabelecidas pela demanda, descobrir as melhores alternativas para derrubar barreiras colocadas pelos colaboradores na implantação, visando aumentar a lucratividade da empresa; identificar quais são as opiniões dos funcionários/colaboradores; elaborar ações baseadas nas percepções das situações vivenciadas pelos funcionários/colaboradores para produção de ações que possibilitem atingir estes objetivos.

Para que este objetivo fosse atingido, planejou-se uma pesquisa baseada na aplicação de um questionário qualitativo a partir de entrevistas, sendo este composto por perguntas básicas sobre o respondente e sua empresa. As perguntas foram elaboradas, levando-se em consideração aspectos que poderiam de certa forma, influenciar o funcionamento da empresa Brazilian Color, tendo o estudo como principal alicerce autores como os citados na revisão de literatura. Apesar da amostra não ser representativa, ela é conveniente em função da disposição dos respondentes em participar da pesquisa e responder o questionário de forma bastante detalhada. Foram entrevistadas 25 pessoas.

\section{Resultados e Discussão}

Os resultados descritos a seguir foram baseados nas informações colhidas nas entrevistas, também foram colhidas informações nos sites da organização. Estas contribuíram para complementar o estudo. Os resultados visaram responder, o planejamento programação e controle de produção, para o cumprimento de datas estabelecidas pela demanda, com base nos sistemas Just in time. As discussões apresentadas buscam traduzir a interpretação do pesquisador, construída a 
partir da análise das respostas obtidas pelas entrevistas realizadas, bem como, os dados obtidos a partir da observação in loco. As informações foram trabalhadas de forma a apresentar as percepções dos colaboradores com a finalidade de elaborar ações que venham a contribuir para Planejamento programação e controle de produção na indústria química.

Quadro 1 - Percepções acerca de planejamento programação e controle de produção para o cumprimento de datas estabelecidas pela demanda, com base nos sistemas Just in time.

\begin{tabular}{l|l} 
Diretores (3) & 1- O PPCP recebe um levantamento de matéria-prima, com a quantidade de cada
\end{tabular} matéria-prima no estoque, depois disso ele processa as informações e verifica as necessidades de compras e envia para o departamento de compras, vendas encaminha os produtos que estão em falta no estoque para que seja produzido, então o PPPC emite e encaminha as ordens de fabricação para as produções e faz a análise do processo produtivo.

2- Continuaria da mesma forma que está sendo realizado.

3- O processo muitas vezes acaba tendo de enfrentar algumas barreiras como um sistema lento, de melhoria sugiro uma implantação de um sistema mais complexo e mais rápido.

4- De melhoria sugiro uma implantação de um sistema mais rápido, de resto acredito que esteja tudo sobre controle.

5- Sim, é um sistema que só é produzido aquilo que é vendido nada é comprado ante da hora para eliminar ao máximo os desperdícios, melhor forma de implantar acredito que de inicio seria bom haver uma preparação de terreno, ou seja, oferecer treinamentos aos colaboradores, pois eles são as células da empresa, é preciso acertar prazos com fornecedores e eliminar todos os estoques da fábrica.

6- Sim, é enviado uma pesquisa mensal para nossos clientes ativos e o retorno e bem positivo.

7- $\mathrm{O}$ gerenciamento de estoque de matéria-prima é realizado por um sistema caseiro que cada tipo de matéria-prima têm um código interno que é aberto na entrada do material, o de produto acabado é realizado também por um sistema caseiro, os colaboradores da expedição incluem no nosso sistema por descrição do produto.

8- Mais atenção do pessoal que realiza a inclusão no sistema, pois o sistema funciona perfeitamente, mais ainda surgem furos de estoques.

1- O Planejamento recebe a contagem de quanto têm de matéria-prima, com essa informação eles geram ordens de compras de matéria-prima, geram ordens de fabricação e encaminham para as produções e fazem o acompanhamento.

2- O processo deveria continuar da mesma forma, só acredito que eles deveriam posicionar mais o nosso setor comercial, pois muitas vezes perdemos vendas, por não ter uma informação concreta.

5- Sim, acredito que nessa organização não daria para estar implantado.

6- Sim, trabalhamos ao máximo para cumprir nossos prazos, todos os pedidos de vendas são negociados o prazo com os clientes.

7- Todo gerenciamento é realizado por um sistema caseiro desenvolvido pelo pessoal do T.I.

8- Sim, muitas vezes aparecem que têm a matéria-prima, mais quando a conferência física o material não está lá, sugiro mais atenção dos colaboradores para o almoxarifado.

1- O processo funciona da seguinte forma, eles emitem as ordens de fabricação e fazem o processo de acompanhamento nas produções.

3- Melhoria, sempre é bom, vejo alguns comentários sobre a agilidade, temos algumas pessoas que ficam amarrando o processo e acaba atrasando algumas coisas.

4- Sugiro ter mais comunicação com os departamentos de compras, vendas.

5- Sim, é um sistema que nada é comprado antes de ter necessidade, para implantar um sistema desse aqui na nossa organização deveria ter um novo planejamento no setor comercial, pois eles que dão o ponta pé inicial, eles são responsáveis para negociar os prazos com os nossos clientes. 


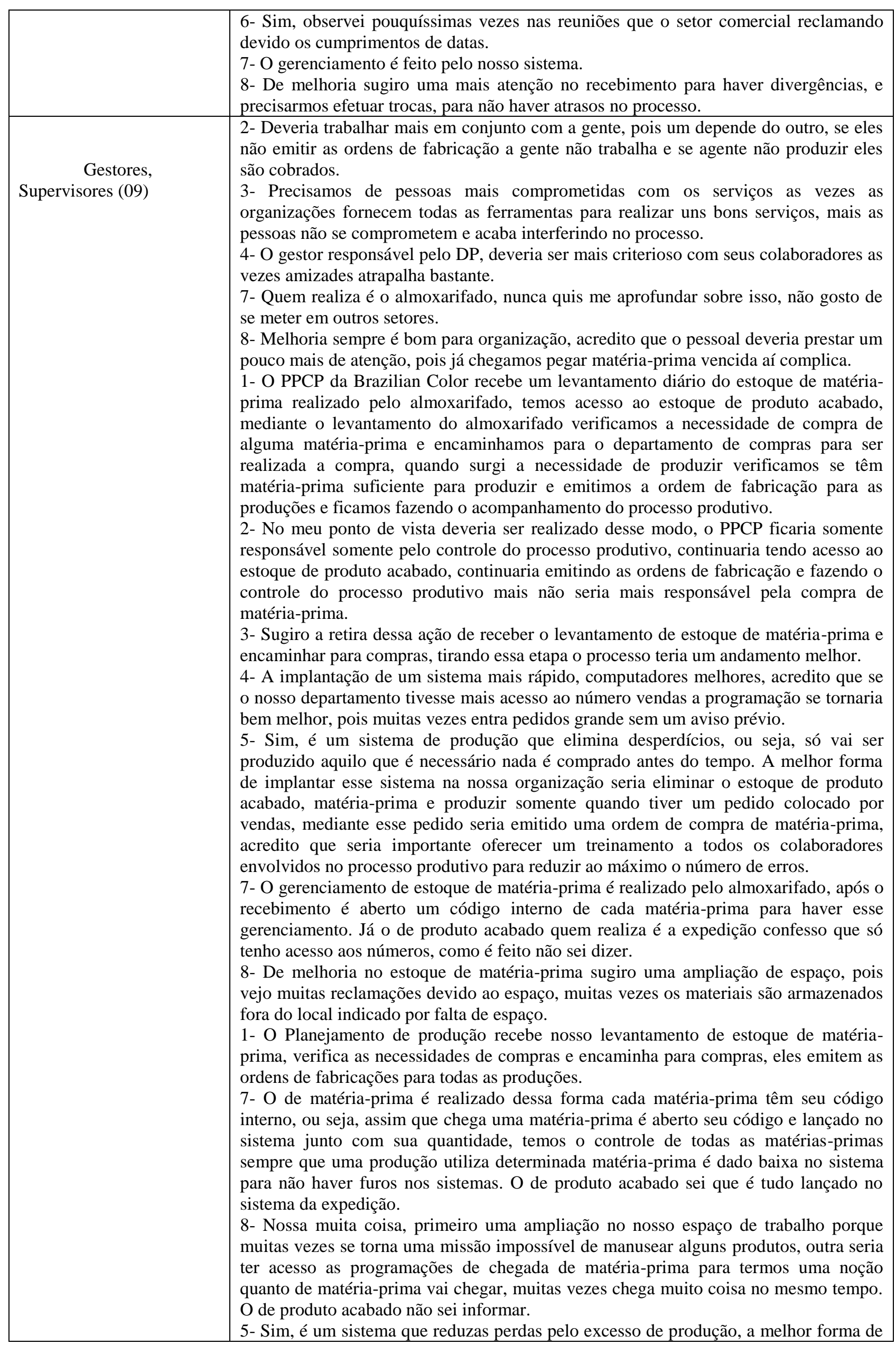

897 


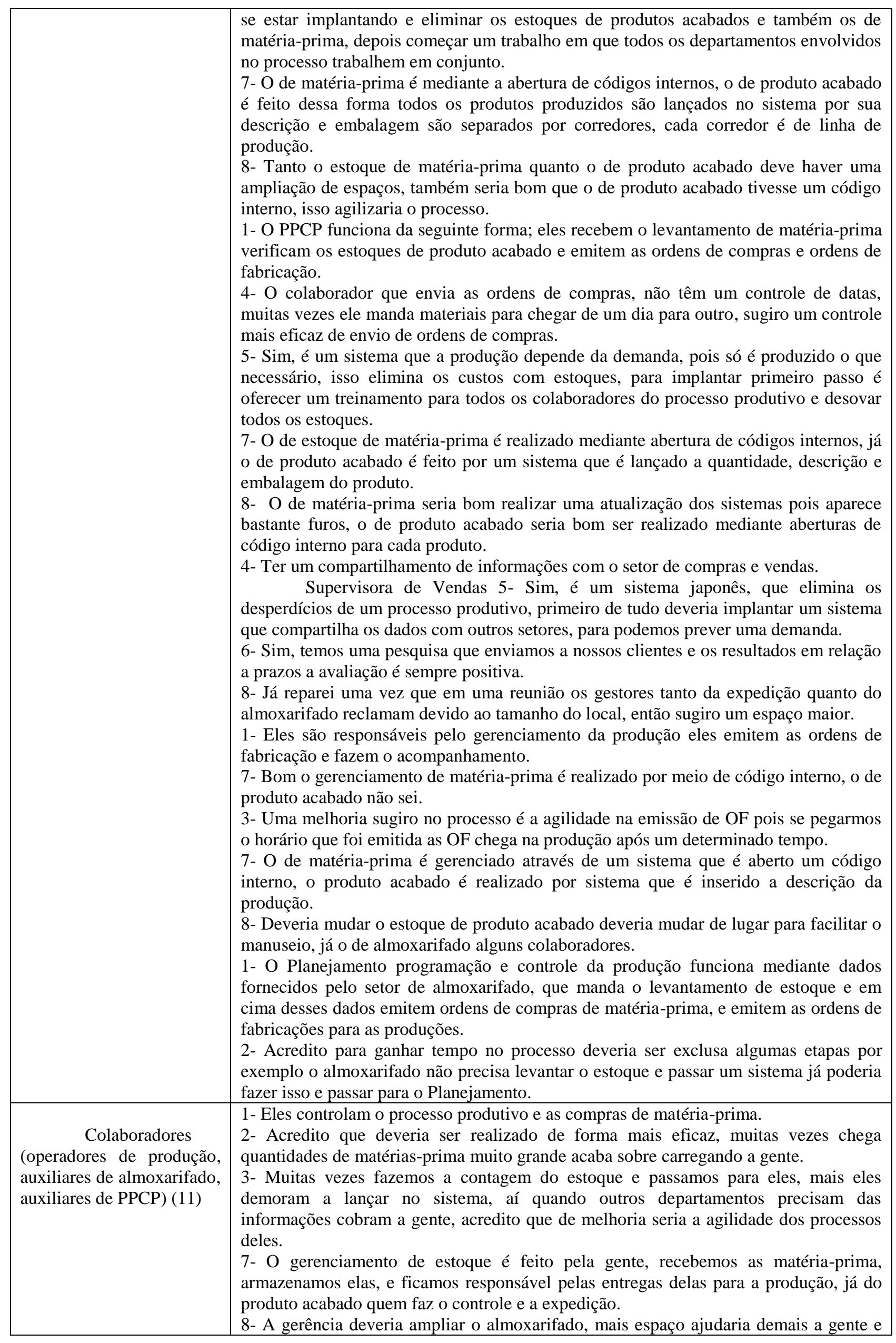


agilizaria o processo, já o de produto acabado já escutei um colaborador da expedição reclamar por falta de carrinhos hidráulicos, acho que compras de carrinhos hidráulicos. 1- O pessoal da programação faz todo o controle de produção, eles geram as ordens de serviços e enviam para as produções.

3- Já ouvi alguns operadores de produção reclamar, dizem que eles demoram um pouco para enviar as ordens de fabricação, então sugiro um pouco mais de agilidade no processo.

4- Sugiro que eles busquem mais informações com o almoxarifado para seja um controle de matéria-prima mais eficaz.

7- Bom o de produto acabado quem realiza é a gente aqui do almoxarifado, a gente realiza o recebimento, conferência e separação de matérias, depois armazenamos nos locais destinados, já o de produto acabado não sei informar.

8- No caso do estoque de matéria-prima eles deveriam ampliar o local de recebimento e armazenamento de matéria-prima, pois muitas vezes o espaço não suporta a quantidade de material.

2- Bom, eles deveriam acompanhar o processo produtivo até o final, não adianta acompanhar só o começo, e deixar o final.

7- $\mathrm{O}$ estoque de matéria-prima é organizado por endereços aonde cada classe de material fica separado, ex. pigmento fica separado de aditivos, para facilitar o manuseio das matérias-primas. No caso da expedição já fui lá em algumas vezes eles fazem o estoque de produto acabado separando linhas de produção ex. industrial é um endereço imobiliária é outro.

8- Bom, no caso de matéria-prima acredito que ampliação de espaços em geral, já no caso da expedição também ampliar espaços, pois quando fui lá estava bastante cheio.

2- Na minha opinião o departamento de compras deveria ter acesso ao levantamento de estoque, para que o próprio departamento realize o controle, fazendo isso o Planejamento de produção seria responsável apenas pelo controle e emissão de ordens de fabricação.

4- Comprometimento de alguns colaboradores, pois têm uns que não sei como ainda estão na organização.

7- O de matéria-prima é realizado por setores que cada espaço fica uma classe de matéria-prima, eles são divididos por corredores, cada produto que sai é dado baixa no sistema, já o de produto acabado não sei informar.

8- Sim o de matéria-prima deveria ter mais espaço e mais colaboradores, pois muitas vezes fica corrido para a gente, sobre o de produto acabado não sei informar.

1- Eles recebem o levantamento de estoque de matéria-prima, enviam ordens de compras e de fabricação e fazem o acompanhamento dos processos produtivos.

2- Eles deveriam receber o levantamento de estoque, emitir somente as ordens de fabricação dos produtos e fazer o acompanhamento do processo.

3- De melhoria sugiro mais atenção no processo de emissão, pois muitas vezes e emitido ordens de fabricação errada, por falta de atenção.

6- Sim, se houver algum atrasado em alguma parte é aviso para o PPCP, para que avisem aos clientes, a empresa se preocupa bastante no cumprimento.

7- Todo matéria-prima que entra é lançado no sistema, o material é separado pela sua classe e quando sai é dado baixa no sistema, o produto acabado não sei informar.

8- Sim, precisamos de um lugar mais amplo, pois o espaço é limitado, e também temos que ter um controle mais eficiente pois muitas vezes aparecem furos no estoque.

1- O almoxarifado realiza o levantamento de estoque de matéria-prima passa para a gente daí verificamos as necessidades de compras e emitimos as ordens de compras, para repor os estoques, emitimos as ordens de fabricação e passamos para as produções.

2- Deveria ser assim, o almoxarifado levanta o estoque de matéria-prima e passa direto para compras sem passar pelo nosso departamento assim ganharíamos tempo, o restante do processo poderia continuar da mesma forma.

4- Uma reformulação de equipe, um sistema mais eficiente, pois o sistema trava muito.

7- Bom, conheço mais afundo o de matéria-prima, sei que divido por classes de materiais que ficam em corredores, quando chega uma matéria-prima e aberto um código interno no sistema, quando esse material sai para produção é dado baixa. Já o de produto acabado não sei informar.

1- O almoxarifado levanta o estoque de matéria-prima passa para gente daí passamos as ordens de compras para o departamento de compras, daí emitimos todas as ordens de fabricação de todas as produções e fazendo o acompanhamento do processo produtivo. 


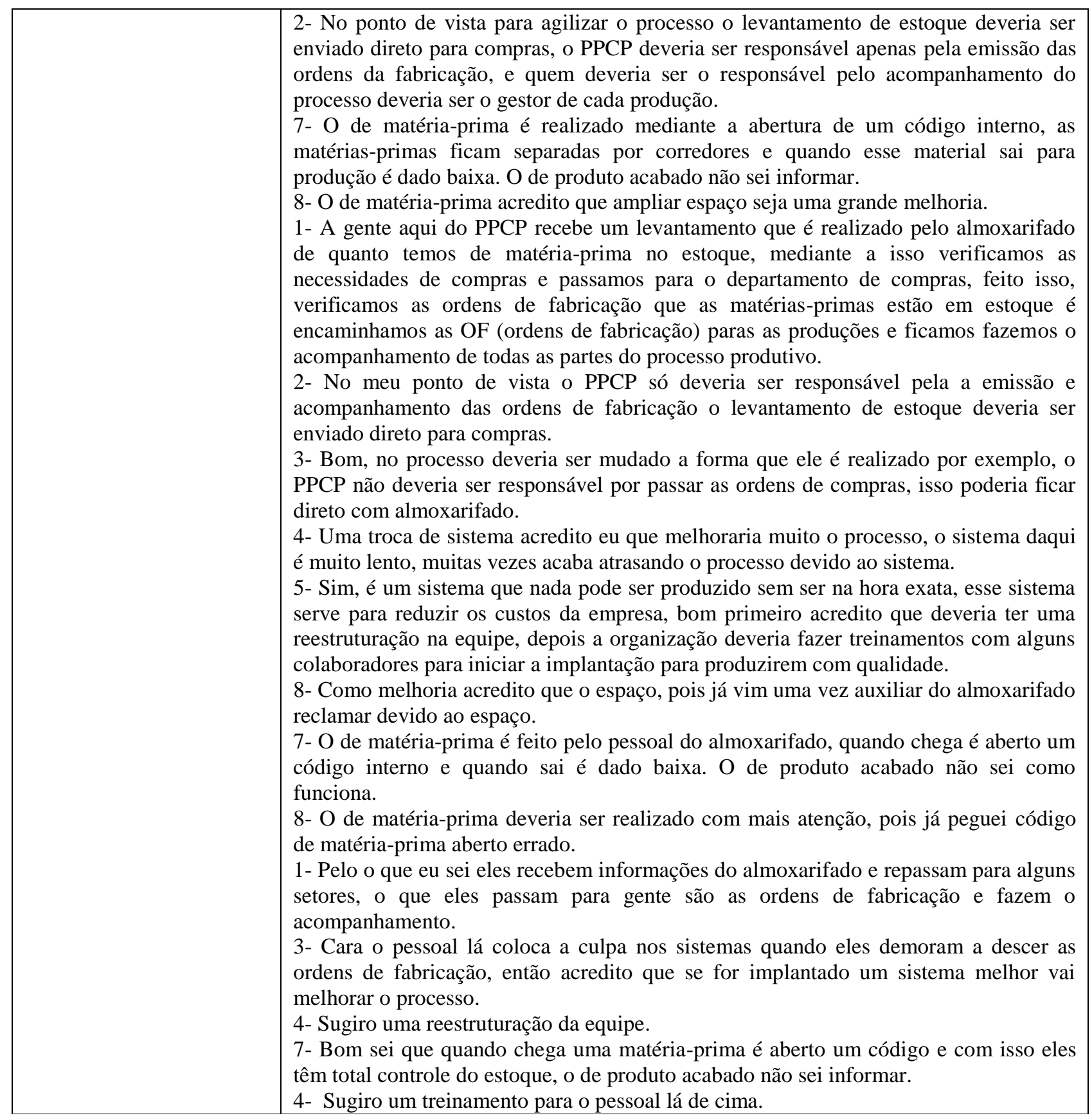

Fonte: Dados das pesquisas

Após serem realizadas as entrevistas foram encontradas algumas semelhanças e diferenças entre alguns colaboradores, as semelhanças que foram encontradas foram que tanto os colaboradores da produção, PPCP quanto os do almoxarifado sugerem uma ampliação dos espaços dos estoques de matéria-prima e pedem a substituição de alguns colaboradores do planejamento programação e controle de produção. A Principal diferença entre os entrevistados foi que os colaboradores do setor de planejamento programação e controle de produção reclamam do sistema, mais os demais colaboradores dos outros departamentos que trabalham em conjunto com o PPCP, não fazem reclamação referente o sistema. 
O sistema de produção que elimina desperdícios, ou seja, só vai ser produzido aquilo que é necessário nada é comprado antes do tempo. A melhor forma de implantar esse sistema na nossa organização seria eliminar o estoque de produto acabado, matéria-prima e produzir somente quando tiver um pedido colocado por vendas, mediante esse pedido seria emitido uma ordem de compra de matéria-prima, acredito que seria importante oferecer um treinamento a todos os colaboradores envolvidos no processo produtivo para reduzir ao máximo o número de erros.

$$
\text { Segundo Plossl (1993) A }
$$
administração deve tomar a liderança no desenvolvimento dos programas educacionais necessários para superar as limitações do passado e preparar todo o seu o pessoal para o futuro; portanto a organização deve tomar ciência que treinamento é fundamental para que os colaboradores estejam preparados para mudanças em equipamentos industriais. BOOG (2009) A firma que eliminar desperdícios significa analisar todas as atividades realizadas na fábrica e descontinuar as que não agregam valor à produção; como também para eliminar alguma atividade do processo produtivo, deve se haver um estudo do processo, para não eliminar alguma que interfere diretamente ao valor do produto acabado, para que o produto seja produzido com um alto padrão de qualidade.

No sistema que só é produzido aquilo que é vendido nada é comprado antes da hora para eliminar ao máximo os desperdícios, melhor forma de implantar acredito que de inicio seria bom haver uma preparação de terreno, ou seja oferecer treinamentos aos colaboradores, pois eles são as células da empresa, é preciso acertar prazos com fornecedores e eliminar todos os estoques da fábrica.

Segundo Harding (1989) para que fossem mantidos estoques adequados de materiais, capazes de manter a produção trabalhando sem interrupções, deveria haver uma sequencia lógica ou uma regra para encomendas; portanto têm que haver um planejamento de vendas, para que não seja colocado pedidos que atropelem o processo produtivo, devido as negociações realizadas com os clientes. Um sistema que nada pode ser produzido sem ser na hora exata, esse sistema serve para reduzir os custos da empresa, bom primeiro acredito que deveria ter uma reestruturação na equipe, depois a organização deveria fazer treinamentos com alguns colaboradores para iniciar a implantação.

Segundo Ritzman (2004) gerenciar o estoque de demanda independente pode ser complicado, porque a demanda é influenciada por fatores externos; porém se ocorrer mais estudo antes de fechar uma negociação, pode se preparar com antecedência a situações que possam ocorrer.

A eliminação de estoques é premente nesse caso serão eliminados os estoques de matéria-prima e produto acabado, só terá 
estoque os produtos de alta saída. Para reduzir as perdas devido às questões de validade, e os custos de manutenção com estoques. Será realizado no setor de almoxarifado, expedição, vendas em um prazo estimado de 1 ano aproximadamente, ficará responsável o gestor de almoxarifado e gestor de expedição e a supervisora de vendas, será realizado do seguinte modo a matéria-prima só será comprada mediante o pedido de venda colocado no sistema, já o de produto acabado seria meio que um sistema de desovar, fazendo promoções.

Com a implantação do sistema JIT será elevada a qualidade do produto acabado da empresa, para que a organização conquiste mais seu mercado de atuação, o departamento responsável por realizar os testes de qualidade será o laboratório de controle de qualidade (LCQ) e o de fiscalizar a qualidade dos produtos será o sistema de gestão integrada (SGI), em prazo de 2 anos aproximadamente, ficará responsável o Gestor de SGI, pois todos produzidos devem sair com um certificado de qualidade, o responsável de emitir esse certificado será o LCQ, e só será liberado mediante a aprovação do SGI.

Deve-se diminuir o máximo o números de erros no processo produtivo, para não gerar retrabalhos ou até mesmo paradas no processo produtivo e não termos imprevistos na físcalização da qualidade do produto e na entrega, todas as produções e o setor de almoxarifado e o departamento de PPCP, deve ser realizado em 1 ano aproximadamente os responsáveis serão todos os gestores de produções e o gestor de PPCP e almoxarifado, os colaboradores e gestores de produções e auxiliares de almoxarifado e PPCP receberam treinamentos, para executar sua função no processo produtivo com excelência.

Será criado um planejamento de vendas, para que seja mantido estoques adequados de produtos acabados e elevar o número de vendas, o departamento responsável pela criação desse planejamento será o departamento de vendas, em um prazo aproximadamente de 1 ano, mediante a responsabilidade do gerente de vendas e supervisora de vendas, será realizado um estudo dos clientes para entender sua necessidade, fazendo isso conseguiremos fazer um planejamento de produção mais eficaz mediante o pedido colocado.

Diante do exposto as implicações mais relevantes são de natureza empírico/gerencial, pois durante a realização da pesquisa constatou-se a necessidade da implantação do sistema Just in Time na organização Brazilian Color que são eixos empírico e gerenciais mais condizentes com as necessidades expressas da organização no atual contexto da empresa). (FLEURY; FLEURY, 2001).

A despeito das limitações da pesquisa, a primeira delas está relacionada à amostra analisada e seu caráter não probabilístico que impedem que os resultados gerados por essa pesquisa sejam generalizados para todo o segmento ou para todas as empresas e, a 
segunda, por se tratar de um caso único, não possibilita a comparação com outras empresas, a fim de identificar as semelhanças e diferenças existentes.

\section{Considerações Finais}

Os objetivos desse trabalho foram refletir a importância do planejamento programação e controle de produção é tão importante para o cumprimento dos prazos de entregas estabelecidos pela demanda na indústria química e verificar os benefícios do planejamento programação e controle de produção visando o cumprimento das datas de entregas dos produtos, com ênfase na produtividade graduada e compreender $\mathrm{o}$ ambiente fabril, para a fábrica trabalhar em total sintonia com o PPCP, para tal foi realizado um estudo de caso, com abordagem qualitativa por meio de entrevistas, na empresa Brazilian Color no setor químico. A revisão de literatura sugere que existe uma relação entre Planejamento e Programação.

Os principais resultados demonstraram que a implantação do sistema do Just in Time na organização Brazilian Color seria a solução para o problema encontrado no PPCP, com essa implantação a empresa terá uma produção enxuta de desperdícios, pois os colaboradores serão treinados para que trabalhem com máximo de eficiência, para não haver erros no processo, pois a empresa não irá trabalhar com estoques.

Como sugestão de estudos futuros, é necessário ampliar a amostra para outras revisões de literatura, ampliar o período de tempo para possibilitar uma visão mais abrangente do emprego dos métodos de pesquisa, podendo apresentar contribuições significativas como, por exemplo, permitir novas contribuições metodológicas na área e ampliar a análise dos resultados e, por fim, a realização de futuras pesquisas ligando o tema planejamento programação e controle de produção e o sistema Just in time com as escolhas metodológicas que se mostrariam relevantes no sentido de verificar tendências e oportunidades de pesquisa, para que os profissionais e gestores da área tenham mais clareza sobre o tema.

A princípio, tinha-se receio de que o questionamento sobre os temas desta pesquisa não fosse bem compreendido pelos colaboradores durante a entrevista, porém foi surpreendente o entendimento deles quanto aos assuntos tratados, acreditando-se que isso se deve pela própria rede de informações que faz parte de seu cotidiano. 
BOOG, G. Manual de Treinamento e Desenvolvimento Processos e Operações. 1. ed. São Paulo: Pearson Prentice Hall, 2009.

BONOMA, T. V. Case Research in Marketing: Opportunities, Problems, and Process. Journal of Marketing Research, Vol XXII, May 1985.

BASTOS, P.T. Gestão da Inovação. 1ed. São Paulo: Elsevier, 2006.

CORRÊA, H.; GIANESI, I.; CAON, M. Planejamento, Programação e Controle da Produção. 4. ed. São Paulo: Atlas, 2001.

COLLIS, J.; HUSSEY, R. Pesquisa em administração: um guia prático para alunos de graduação e pós-graduação. 2.ed. Porto Alegre: Bookman, 2005.

DUARTE, G. Dicionário de Administração e Negócios. 1. ed. Ceará: K, 2011.

FLORES, J. F. Análisis de dados cualitativos - aplicaciones a la investigación educativa. Barcelona: PPU, 1994.

FACHIN, O. Fundamentos de metodologia. 4. ed. São Paulo: Saraiva, 2003.

FLEURY, M. T. L.; FLEURY, A. Construindo o conceito de competência. RAC, edição especial 2001, p.p. 183-196.

GIL, A. C. Métodos e técnicas de pesquisa social. 6. ed. São Paulo: Atlas, 2008. 220 p

GUBRIUM, J. F.; HOLSTEIN. Analyzing Interpretative Practice. In: DENZIN, N. K.; 2000.

HARDING, H.A. Administração da

Produção. 1. ed. São Paulo: Atlas, 1989.

MERRIAM, S.B.: Qualitative research and case study applications in education. 2 . ed. San Francisco: Jossey Bass, 1998.

MOREIRA, A. Administração da produção e operações. 2.ed. São Paulo: Cengace Learning, 2008.
OFENHEJM, A.M. Gestão Estratégica de Pessoas. 1. ed. São Paulo: Cengage Learning, 2008.

OLIVEIRA, A.A.N. Introdução à Engenharia da Produção. 1.ed. São Paulo: Visual Books, 2006.

PLOSSL, G.W. Administração da Produção. 1. ed. São Paulo: Makron Books, 1993.

RAMOS, P.; RAMOS, M. M.; BUSNELLO, S. J. Manual prático de metodologia da pesquisa: artigo, resenha, projeto, TCC, monografia, dissertação e tese. 2005.

REBOUÇAS, D. Administração de Processos. 4.ed. São Paulo: Atlas, 2011.

RITZMAN, L.; KRAJEWSKI, L. Administração Produção e Operações. 1. ed. São Paulo: Pearson Prentice Hall. 2004.

ROCHA, D. Gestão da produção e operações. 1.ed. Rio de Janeiro: Ciência Moderna, 2008.

RYNES, S., GEPHART, R. P., JR. From the editors: qualitative research and the Academy of Management Journal. Academy of Management Journal, 47 (4), 454-461. 2004.

SILVA, R.L. Controles na Produção. 2ed. São Paulo: Cepai, 1973.

SLACK, N.; CHAMBERS, S.; JOHNSTON, R. Administração da Produção. 2. ed. São Paulo: Atlas, 2002.

TULL, D. S. \& HAWKINS, D. I. - Marketing Research, Meaning, Measurement and Method. Macmillan Publishing Co. Inc., London, 1976.

YIN, R.K. Estudo de caso: planejamento e métodos. 3. ed. Porto Alegre: Bookman, 2005. 